\title{
Design of Broadband Rectangular Microstrip Patch Antenna Inset ' $L$ ' Shaped Feed with Rectangular ' $L$ ' Slots in Ground Plane
}

\author{
Bimal Garg, Rahul Tiwari, Ashish Kumar and Sunil Kumar Thakur \\ Department of Electronics Engineering, \\ Madhav Institute of Technology \& Science, \\ Gwalior, India
}

\begin{abstract}
This paper proposes a patch antenna that uses metamaterial as base construction. Design methodologies including the metamaterial and patch antenna have been explained in detail. The simulation results show that an antenna with metamaterial substrate has improved bandwidth and return loss significantly without changing the frequency. The new inspired metamaterial antenna contributes the best return loss of more than $-22 \mathrm{~dB}$ and $386 \mathrm{MHz}$ bandwidth wider than the conventional patch antenna. This type of antenna is able to take advantage of wireless applications.
\end{abstract}

\section{Keywords}

Rectangular Microstrip Patch Antenna, Metamaterial.

\section{INTRODUCTION}

The demand on the portable mobile devices is increasing progressively with the development of novel wireless communication techniques. In that respect, compact size, light weight, low profile and low cost are now quite important challenges to be accomplished by the designers for every wireless mobile component [4]. Recently, there is growing research activity on multi-frequency and wideband antennas for various wireless applications such as WLAN (Wireless Local Area Network) or WiMAX (Worldwide Interoperability for Microwave Access). In particular this paper, a great interest in wideband antenna for use in wireless communication has been presented. The wideband antenna Preferred over narrow band antennas because of the usage in various applications [3]. A Microstrip or Patch Antenna [2] is a low profile Antenna that has a number of advantages over other antennas it is lightweight, inexpensive, and easy to integrate with accompanying electronics. But use of Rectangular Microstrip Patch Antenna alone is very difficult because of its low gain and narrow bandwidth. So to overcome these problems an artificial material called Metamaterial is incorporates. Metamaterial [1] are an artificial material engineered to provide properties which are not readily available in nature. We have utilized the Metamaterial Structure on the Rectangular Microstrip Patch Antenna to improve its performance [5].

\section{GEOMETRY PROCEDURE \\ AND DESIGN}

The proposed antenna based on the rectangular patch antenna which must be designed first. The antenna is planar rectangular patch antenna fed by microstrip line on the PCB (print circuit board) FR4 substrate with dielectric constant 4.4, loss tangent 0.02 and $1.6 \mathrm{~mm}$ of thickness (h). This antenna is design at frequency $3.188 \mathrm{GHz}$, width of microstrip is $3.009 \mathrm{~mm}$ for match impedance with $50 \mathrm{ohms}$ of transmission line. The Rectangular Microstrip Patch Antenna is shown in figure 1. Then, the Rectangular ' $L$ ' Slots are placed in ground plane in order to study its influence, and the results are compared with those of the antenna alone. The required specifications of this design are shown in the Figure 4.

\subsection{Design of Rectangular Microstrip Patch Antenna Inset L-Shaped Feed}

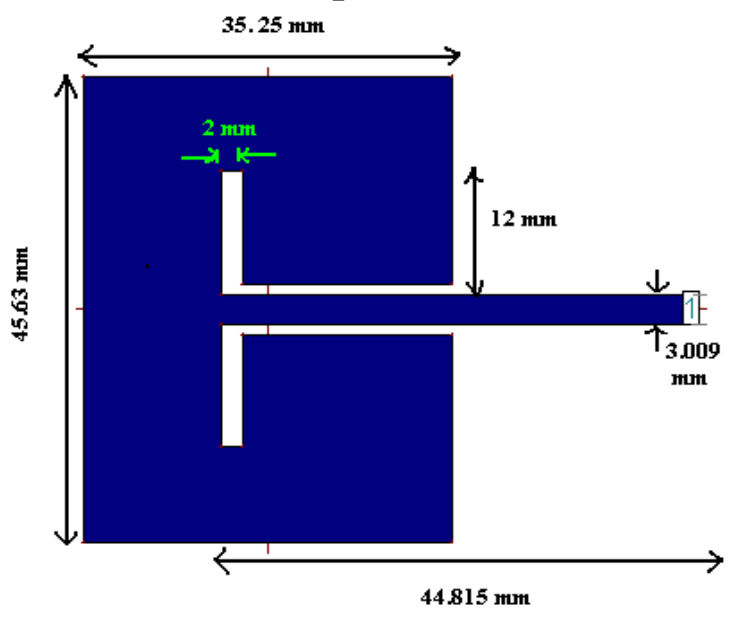

Figure 1: Rectangular Microstrip Patch Antenna 


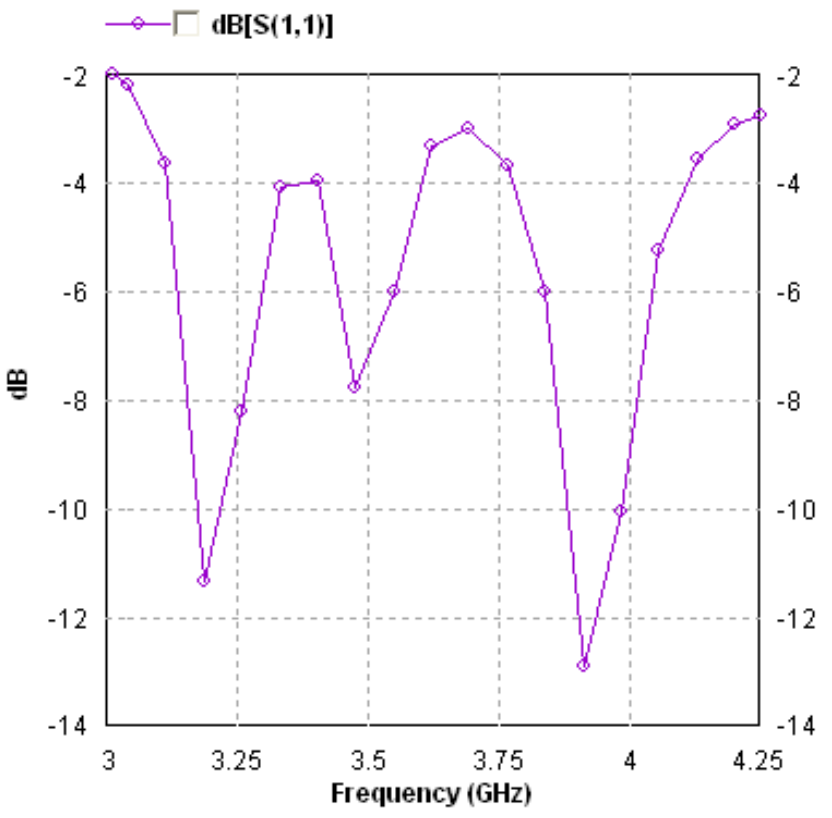

Figure 2: Simulation of Return Loss of Rectangular Microstrip Patch Antenna

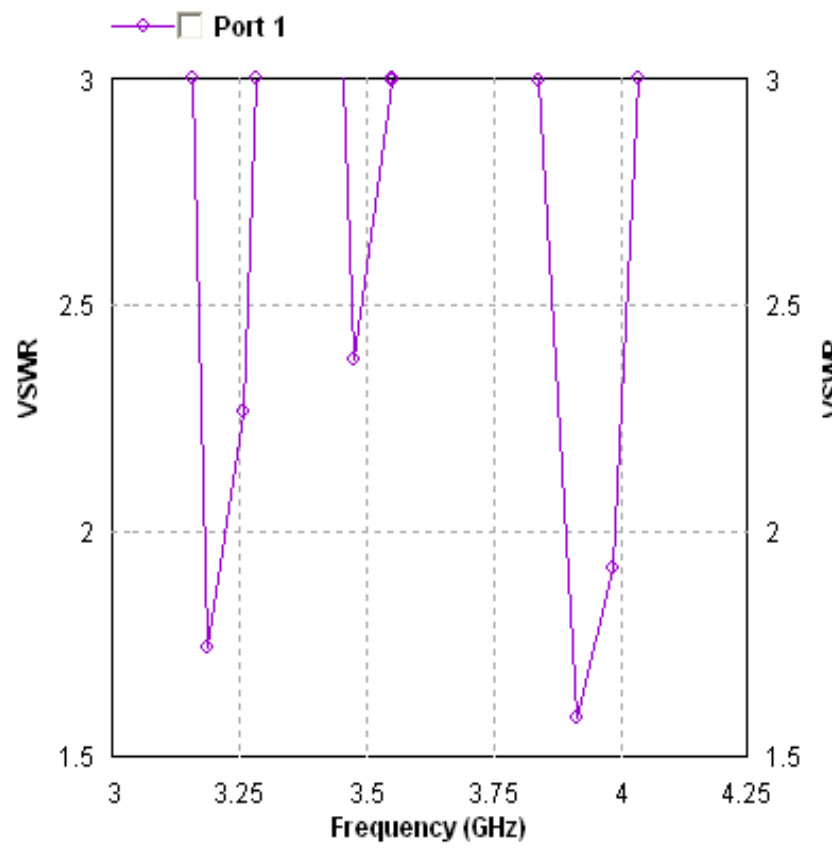

Figure 3: VSWR of Rectangular Microstrip Patch Antenna

\subsection{Metamaterial Design of Rectangular Microstrip Patch Antenna Inset L-Shaped Feed}

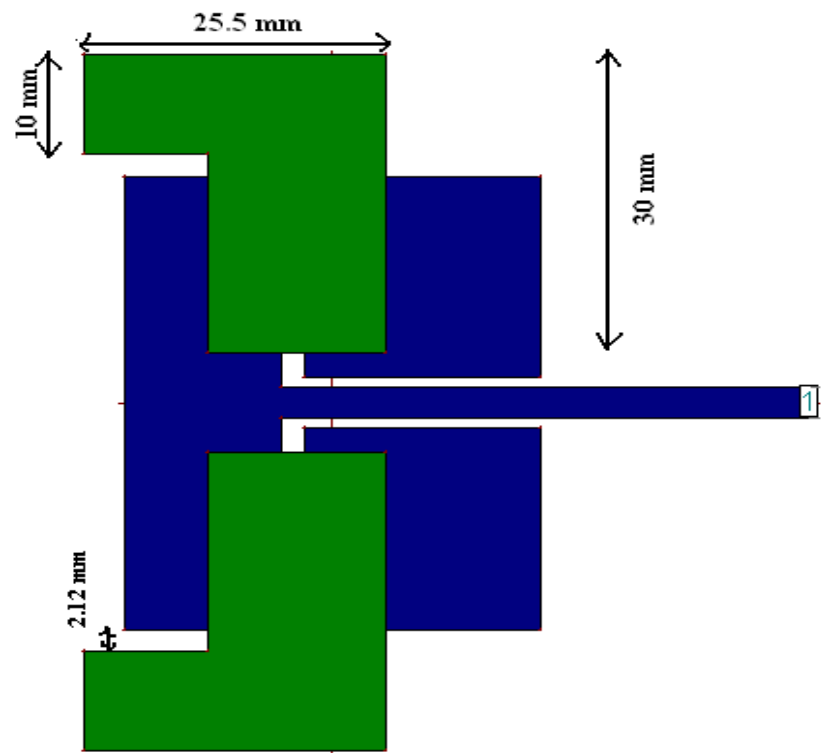

Figure 4: Rectangular Microstrip Patch Antenna with Ground Plane Structure.

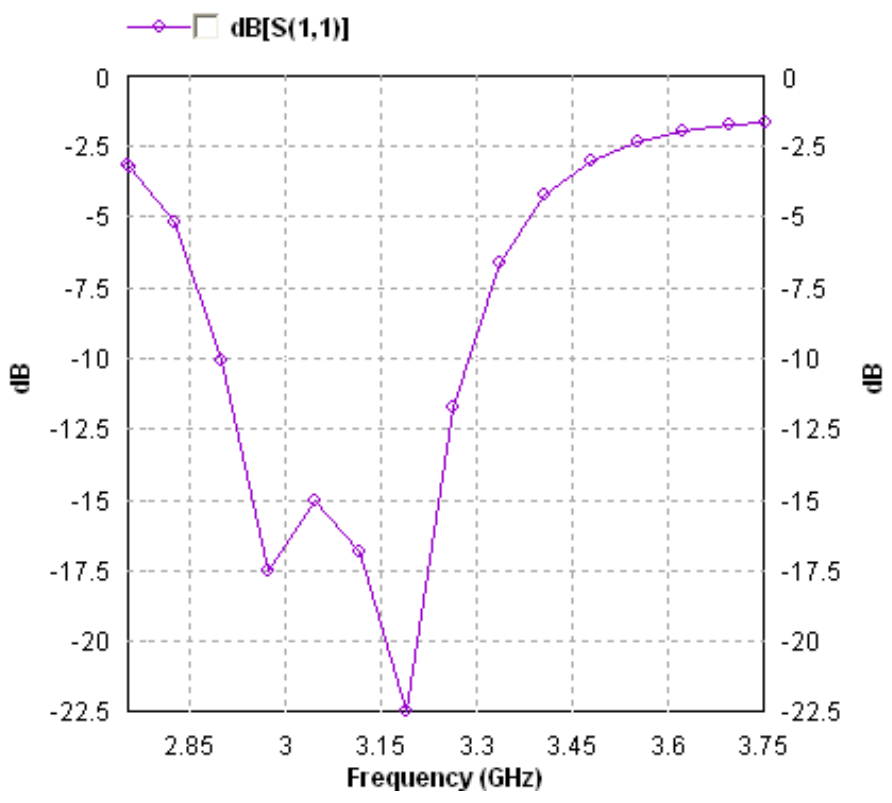

Figure 5: Simulation of Return Loss of Rectangular Microstrip Patch Antenna with Ground Plane Structure 


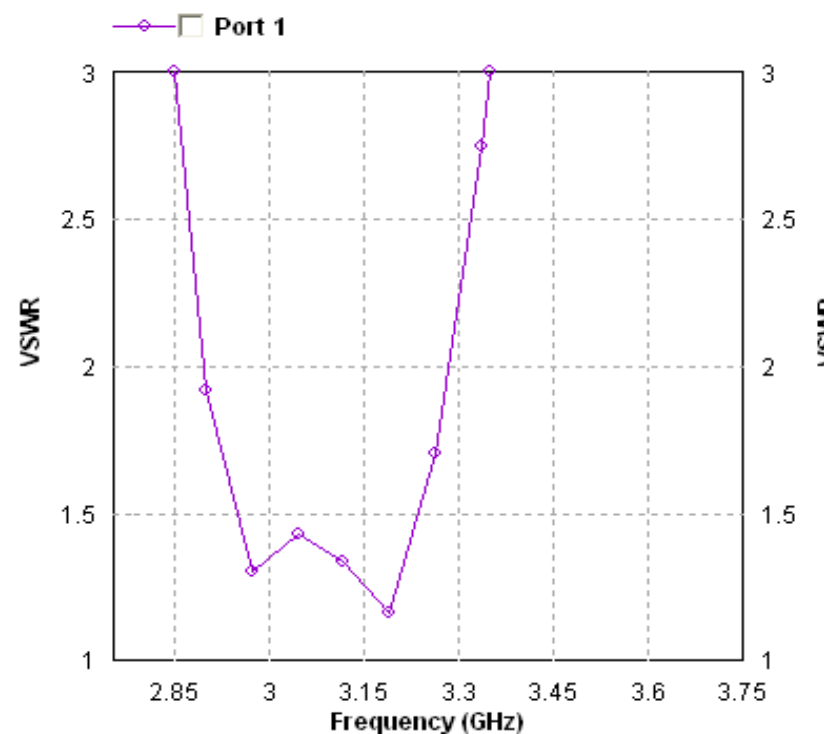

Figure 6: VSWR of Rectangular Microstrip Patch Antenna With Ground Plane Structure

$-\Gamma \mathbf{s}(\mathbf{1}, \mathbf{1})$

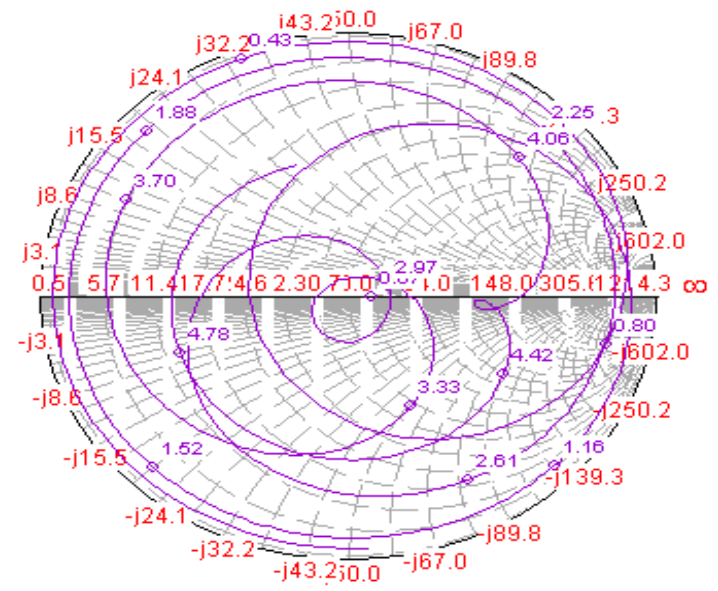

Figure 7: Smith Chart of Rectangular Microstrip Patch Antenna with Ground Plane Structure

\section{METHODOLOGY [2]}

\subsection{Width of metallic patch $(\mathrm{W})$}

$W=\frac{1}{2 f_{r} \sqrt{\mu_{0} \varepsilon_{0}}} \sqrt{\frac{2}{\varepsilon_{r}+1}}=\frac{C}{2 f_{r}} \sqrt{\frac{2}{\varepsilon_{r}+1}}$

Where,

$\mathrm{c}=$ free space velocity of light

$\varepsilon_{\mathrm{r}}=$ Dielectric constant of substrate
The effective dielectric constant of the Microstrip antenna to account for fringing field.

\subsection{Effective dielectric constant is calculated from}

$$
\varepsilon_{e f f}=\frac{\varepsilon_{r}+1}{2}+\frac{\varepsilon_{r}-1}{2}\left(\frac{1}{\sqrt{1+\frac{12 h}{w}}}\right)
$$

\subsection{Length of metallic patch $(\mathrm{L})$}

$\mathrm{L}=\mathrm{L}_{\mathrm{eff}}-2 \Delta \mathrm{L}$,

where

$$
\mathrm{L}_{\mathrm{eff}}=\frac{C}{2 f_{r} \sqrt{\varepsilon_{e f f}}}
$$

\subsection{Calculation of Length Extension}

$$
\frac{\Delta L}{h}=0.412 \frac{\left(\varepsilon_{e f f}+0.3\right)\left(\frac{w}{h}+0.264\right)}{\left(\varepsilon_{e f f}-0.258\right)\left(\frac{w}{h}+0.8\right)}
$$

\subsection{Calculation of VSWR}

$\operatorname{VSWR}=\mathrm{S}=\frac{1+|\Gamma|}{1-|\Gamma|}$

Where $\Gamma=$ Reflection Co-efficent

\subsection{Calculation of Return Loss}

Return Loss $=20 \log |\Gamma|$

\section{SIMULATION RESULTS}

A Research on Metamaterial was carried out to understand the fundamentals of the newly discovered substance. Then, the IE3D simulation software V.10 was chosen to simulate the structures shown in the Figures. The S-parameter was obtained from simulation. The simulated result of Rectangular Microstrip Patch Antenna and Rectangular Microstrip Patch Antenna with Ground Plan metamaterial Structure are shown in figure 2 and 5. At $3.188 \mathrm{GHz}$ frequency simulated Rectangular Microstrip Patch Antenna alone exhibits the Return Loss of $-11.33 \mathrm{~dB}$ and Bandwidth improvement $43.29 \mathrm{MHz}$ while when it is incorporated with Rectangular L Slot structure at the Ground Plan. It shows Return Loss around $-22.43 \mathrm{~dB}$ and Bandwidth improvement $386.77 \mathrm{MHz}$. The enhancement in Bandwidth near about $0.343 \mathrm{GHz}$ was achieved and Antenna was used for wide band applications. 


\section{CONCLUSION}

In this work it is found that the insertions of inspired Meta material structure at ground plane on Rectangular Microstrip Patch Antenna ultimately enhances Bandwidth significantly. This had also been proven that the focusing effect of Metamaterial really reduces Return Loss as well as improve Gain and Directivity of such types of Antenna.

\section{REFERENCE}

[1] V.G. Veselago "The electrodynamics of substances with simultaneously negative value $\varepsilon$ and $\mu$ " Sov. Phys. Uspekekhy.10 (4), 509-514(1968).

[2] Constantine A.Balanis, Antenna Theory and Design. John Wiley \& Sons, Inc., 1997.
[3] S. Satthamsakul, N. Anantrasirichai, C. Benjangkaprasert and T. Wakabayashi, "Rectangular Patch Antenna with Inset Feed and Modified Ground-Plane for Wideband Antenna," SICE Annual Conference 2008 August 20-22, 2008, The University Electro-Communications, Japan.

[4] Merih Palandoken, Andre Grede, and Heino Henke, "Broadband Microstrip Antenna with Left-Handed Metamaterials," IEEE TRANSACTIONS ON ANTENNAS AND PROPAGATION, VOL. 57, NO. 2, FEBRUARY 2009.

[5] Bimal Garg, Rahul Tiwari, Ashish Kumar, Tilak Chitransh, "Design of Factored "X" Shaped Metamaterial Structure for Enhancement of Patch Antenna Gain," csnt, pp.232-235, 2011 International Conference on Communication Systems and Network Technologies, 2011 